\title{
Temporomandibular disorders and oral habits in high-school adolescents: a public health issue?
}

\author{
Disfunção temporomandibular e sua relação com hábitos parafuncionais em adolescentes estudantes do \\ ensino médio: um problema de saúde pública?
}

Carolline Bronzeado de OLIVEIRA'

Jully Anne Soares de LIMA ${ }^{1}$

Pâmela Lopes Pedro da SILVA'

Franklin Delano Soares FORTE 1

Paulo Rogério Ferreti BONAN ${ }^{1}$

André Ulisses Dantas BATISTA'

\section{ABSTRACT}

\section{Objective}

Determine the prevalence of signs and symptoms of temporomandibular disorder (TMD) and its relationship with parafunctional habits in a sample of adolescents.

\section{Methods}

The sample consisted of 129 high school students, between 16 and 19 years old in public schools. Data were collected through: a questionnaire about parafunctional habits and TMD symptoms, the Fonseca's index (DMF) and a summarized protocol of clinical evaluation of the TMD signals. These data were analyzed in a descriptive way, using statistical analysis by Chi-square test (x2) and Fisher's Exact test.

\section{Results}

$84.5 \%$ of individuals showed a degree of auto-reported dysfunction. The most frequent parafunctional habit was chewing gum (65.9\%) while the habit of biting objects was significantly associated with the presence of TMD symptoms $(p=0.042)$. There was a statistically significant association between TMD symptoms with variables such as gender $(p=0.032)$ habits $(p=0.014)$ and emotional stress $(p<0.01)$, besides the association between the need of treatment and gender $(p=0.002)$ and stress $(p<0.01)$. In addition, there was an association between muscle tenderness, unilateral mastication $(p=0.045)$ and chewing ice / lollipop $(p=0.04)$.

\section{Conclusion}

It was concluded that there was not only a high incidence of signs and symptoms of temporomandibular dysfunction and parafunctional habits in high school students, but also an association among them, becoming necessary to establish public policies of prevention and access to treatment for these problems for that specific age group.

Indexing terms: Adolescents. Habits. Oral health. Temporomandibular joint disorders.

\section{RESUMO}

\section{Objetivo}

Verificar a prevalência de sinais e sintomas de disfunção temporomandibular e sua relação com hábitos parafuncionais em uma amostra de adolescentes.

\section{Métodos}

A amostra foi constituída de 129 estudantes, de 16 a 19 anos de escolas públicas de ensino médio. Os dados foram coletados por meio de: um questionário sobre os hábitos parafuncionais e sintomas de disfunção temporomandibular, o Índice anamnésico DMF de Fonseca e um protocolo resumido de avaliação clínica de disfunção temporomandibular. Os dados foram analisados de forma descritiva, com a análise estatística realizada pelo Teste Qui-quadrado (x2) e Exato de Fisher.

\section{Resultados}

Houve prevalência de $84,5 \%$ de indivíduos com algum grau de disfunção temporomandibular. O hábito parafuncional mais frequente foi o de mascar chicletes $(65,9 \%)$ e o hábito de morder objetos teve associação significativa com a presença de disfunção temporomandibular $(p=0,042)$ Houve associação estatisticamente significante entre sexo e disfunção temporomandibular $(p=0,032)$, disfunção temporomandibular e hábitos $(p=0,014)$, disfunção temporomandibular e tensão emocional $(p<0,01)$ e tensão e necessidade de tratamento $(p<0,01)$. Além disso, houve associação entre sensibilidade muscular e mastigação unilateral $(p=0,045)$ e mastigação de gelo/pirulitos $(p=0,04)$.

\section{Conclusão}

Conclui-se que nos adolescentes do ensino médio houve alta prevalência de disfunção temporomandibular e hábitos parafuncionais, bem como a associação entre os dois, sendo necessário o estabelecimento de políticas públicas de prevenção e acesso a tratamento para esse problema e grupo etário específico.

Termos de indexação: Adolescente. Hábitos. Saúde bucal. Transtornos da articulação temporomandibular.

\footnotetext{
${ }^{1}$ Universidade Federal da Paraíba, Centro de Ciências da Saúde. Cidade Universitária, 58051-900, João Pessoa, PB, Brasil. Correspondência para / Correspondenceto: AUD BATISTA. E-mail: <andreulisses@yahoo.com.br>.
} 


\section{INTRODUCTION}

Temporomandibular disorder (TMD) is a term that encompasses a number of changes and disorders that affect the temporomandibular joint (TMJ) and / or the masticatory muscles and associated structures. The TMD may have a variety of signs and symptoms. Pain is the most common symptom; joint pain itself, in the masticatory muscles and the auricular region. Other common signs and symptoms are: joint sounds, limitations to mouth opening, jaw deviation when speaking, swallowing, chewing, mouth opening and / or closing, oral changes in masticatory functions, auditory symptoms and associated parafunctional habits'.

Studies aimed at the epidemiological survey of TMD show that more than $50 \%$ of the population has one or more symptoms of such dysfunction ${ }^{1-2}$, reaching up to $75 \%$ of the adult population ${ }^{3}$. Although their prevalence is not well known, these signs and symptoms are also observed in children and adolescents. Seine et al. ${ }^{4}$ in a bibliographical survey made from 17 studies published between 1990 and 2012, which evaluated the prevalence of TMD in children and adolescents, found that the prevalence of TMD in adolescents was varied, observing a frequency from $16 \%$ to $68 \%$, which can be explained by the different forms of its diagnosis.

Although the TMD presents multifactorial etiology, it is possible to identify the etiology and / or predisposing factors which allow us to prevent and treat it as well as halt its evolution ${ }^{5}$. If diagnosed early, the temporomandibular disorders can be treated avoiding major problems in adulthood $^{6}$. It is quite relevant when assessing the adolescent population, who are often exposed to possible risk factors of TMD development. However, due to the lack of proper education or information and prevention policies they do not often understand the risks of developing future problems with great loss of life quality?

Among these risk factors are the parafunctional habits that promote non-functional neuromuscular activities of the stomatognathic system, producing hyperactivity of some muscle groups and leading to repetitive microtrauma on the joints surfaces which may contribute to the TMD development ${ }^{8}$. Among them are: chewing gum; daytime clenching; bruxism; thumb sucking, tongue thrusting, lip or cheek sucking; blanket, bed sheet, pillow case sucking; onychophagia; biting lips; prone sleeping position, among others ${ }^{6,9}$ Besides parafunctions, there are other potential psychological risk factors identified in patients with the disease. Stress, psychosocial factors, depression and anxiety are common in these individuals and also lead to an impact in the individual social function, regardless their age group ${ }^{6-7,10-12}$

Parafunctional habits are very common in adolescents $^{8}$, but the literature about TMD studies in adolescents is scarce, also there are few studies to relate TDM and parafunctional habits for this age group ${ }^{8-9,13}$. These findings emphasize the need for further studies regarding the TMD prevalence and associated factors because of its high prevalence in the population and high social and personal costs. In addition, there is a lack of public policies that aim to spread the disease and treat individuals with TMD. The number of assistance provided by the state is very low. In addition, the lack of information and specialized services in the treatment mean that there is an insistent search for other specialties dealing with similar symptoms but do not promote adequate control of the disease. Thus, one can consider TMD as a public health problem ${ }^{3}$.

Thus, this study aims to evaluate the prevalence of signs and symptoms of temporomandibular dysfunction and its relationship with parafunctional habits in individuals between 16-19 years old (age group hardly covered in the studies and which is estimated to have a high prevalence of parafunctions), students from public schools in the city of João Pessoa - PB.

\section{METHODS}

It is a non-probabilistic cross-sectional study, conducted with students between 16 and 19 years old of public institutions in the city of João Pessoa in 2010. The sample consisted of 129 students of both gender, aged between 16 and 19, randomly chosen for our convenience, who were enrolled in the two last high school years in five schools which accepted to participate in the experiment. The participants who had not got a Free and Clarified Consent Term signed by their parents or legal representative were excluded from the sample group as well as students who were outside the selected age group and patients who were undergoing orthodontic treatment because these could be confounding variables.

Following the criteria and requirements established by resolution n. 196/96 of the National Health Council (NHC)) the project was presented to the Ethics Research Committee of the Health Science center / UFPB, having its protocol n. 213/10 approved. 


\section{Evaluation of TMD and parafunctional habits}

Data were collected through a questionnaire about personal data and Fonseca's anamnesis questionnaire ${ }^{14}$, answered by the students. The questionnaire for assessing the existence and degree of TMD consists of 10 questions, and for each question there are three possible answers: "yes", "no" or "sometimes"; to which have been assigned the values "10", "0", "5", respectively. The sum of the values attributed to the answers were compared with the index recommended by Fonseca et $\mathrm{al}^{15}$. The total number of points established were 0-15 (no TMD), 20-40 (mild TMD) of 45-65 (moderate TMD) and 70-100 (severe TMD). The data from the DMF anamnesis index allowed us even to classify the sample according to the presence / absence of need for treatment, "no treatment" (no TMD and mild TMD) and "in need of treatment" (moderate $T M D$ and severe $T M D)^{15}$. The latter were sent to a referral service.

The questionnaire also included questions related to TMD symptoms commonly experienced, adapted from other works ${ }^{8-9,13}$, such as the feeling of noise in the temporomandibular joint during movement, if there was a crash when opening and closing the mouth, a pain during chewing and fatigue during mastication, temporomandibular joint pain, difficulty in performing jaw movements, pain in the jaw or face at rest.

Regarding parafunctional habits, it was requested that students described which habits they held more often, in a multiple choice question containing alternatively the following oral habits. teeth grinding, clenching, biting objects (eg. pencils) chewing gum, ice and/or lollipops and unilateral chewing , biting the nails and cheeks, tongue thrusting, thumb and lip sucking and prone sleeping position. Participants were informed that they could point out all the habits they had. Parafunctional habits were divided into two groups: those who reported any of the habits ("presence of habits"), and other individuals who did not have any habit ("no habits").

\section{Evaluation of TMD clinical signs}

After completing the questionnaire, a summarized protocol of the clinical evaluation of DTM ${ }^{8-9,13,16}$ was made containing the muscle palpation and assessment of joint and jaw movement. An examiner previously regulated by an experienced professional in the field, with Kappainter coefficients and intra-examiner of 0.80 and 0.90 , respectively, held the simplified clinical examination at school, in rooms selected by the institutions.

The exam was conducted in a private room with the students sitting on a chair with a backrest, under ambient light with the examiner respecting biosafety principles (using a lab coat, hat, mask and gloves).

The presence of clinical signs allowed to classify the TMD signals according to the following criteria ${ }^{16}$ : muscle sensitivity, two or more sites of muscle pain, articular signs, two or more deviations of the normal site of TMJ (pre and post-condylar sensitivity; deviation; deflection; click; crepitus).

\section{Data analysis}

The data were recorded and tabulated in Statistical Package for Social Sciences (SPSS), version 13.0, and analyzed using descriptive and inferential statistics. For descriptive procedures, it was presented the frequencies and percentages, and for the statistical inference procedures, were used the non-parametric tests : Chi-square $\left(x^{2}\right)$ or Fisher's exact test to identify associations between the variables. In all statistical tests, it was used a 95\% confidence interval and a significance level of $5 \%(p<0.05)$.

\section{RESULTS}

The sample of this study was composed of 129 students, aged between 16 and 19 years old. Eighty-five were women equivalent to $65.9 \%$ and 44 were men corresponding to $34.1 \%$ of the sample.

It was observed that $84.5 \%$ of the sample presented some TMD degree. The majority of them, $54.3 \%$ had mild TMD, while $24 \%$ presented moderate TMD and only $6.2 \%$ severe TMD. Only $7 \%$ of the women sample and $8.5 \%$ of the men sample had no TMD. Of the 44 men, 33 had some degree of TMD. Of the 85 women, 76 had some degree of TMD. There was no severe TMD in men.

Table 1 shows the relationship between the absence and presence of TMD symptoms and between the need for TMD treatment (DMF Index) and its variables: gender, emotional stress and habits, analyzed by the chi-square test. It was found that there was a statistical association between TMD and the women, as well as the presence of stress and parafunctional habits. The need for treatment was statistically related to gender and stress, but not with the presence of parafunctional habits. Analyzing the answers of the DMF index, the question that most often got the answer "yes" was whether the patient had any oral habits for $(78.3 \%)$ of the sample, followed by emotional stress (33.3\%) and the presence of joint sounds (25.6\%). There was a high prevalence of individuals with parafunctional habits (91.5\%), being chewing gum the most common habit in the sample (65.9\%), followed by chewing ice / lollipops (57.4\%) and lip sucking (53.5\%). 
Table 1. Association between absence and presence of TMD symptoms (TMD index) and need for treatment (moderate and severe TMD) in terms of gender, stress and habits. João Pessoa (PB), 2010.

\begin{tabular}{|c|c|c|c|c|c|c|c|}
\hline \multicolumn{8}{|c|}{ TMD symptons } \\
\hline \multicolumn{2}{|c|}{ Variables } & \multicolumn{2}{|c|}{ Absence } & \multicolumn{2}{|c|}{ Presence } & \multirow{2}{*}{ value of $p$} & \multirow{2}{*}{ IC $95 \%$} \\
\hline & & $\mathbf{n}$ & $\%$ & $\mathbf{n}$ & $\%$ & & \\
\hline gender & Men & 11 & 8,5 & 33 & 25,6 & $0,032 *$ & $0,13-0,93$ \\
\hline Stress & No & 13 & 10,1 & 19 & 14,7 & $<0,01 *$ & - \\
\hline \multirow[t]{3}{*}{ Habits } & No & 5 & 3,9 & 6 & 4,7 & \multirow{2}{*}{$0,014 *$} & \multirow{2}{*}{$1,5-21,0$} \\
\hline & Yes & 15 & 11,6 & 103 & 79,8 & & \\
\hline & \multicolumn{7}{|c|}{ Necessity for Treatment } \\
\hline \multirow[t]{2}{*}{ gender } & Women & 51 & 39,5 & 34 & 26,4 & \multirow{2}{*}{$0,002 *$} & \multirow{2}{*}{$0,09-0,62$} \\
\hline & Men & 38 & 29,5 & 6 & 4,7 & & \\
\hline \multirow[t]{2}{*}{ Stress } & No & 30 & 23,3 & 2 & 1,6 & \multirow{2}{*}{$<0,01 * *$} & \multirow{2}{*}{$2,18-42,79$} \\
\hline & Yes & 59 & 45,7 & 38 & 29,5 & & \\
\hline \multirow[t]{2}{*}{ Habits } & No & 10 & 7,8 & 1 & 0,8 & \multirow{2}{*}{0,17} & \multirow{2}{*}{$0,61-39,1$} \\
\hline & Yes & 79 & 61,2 & 39 & 30,2 & & \\
\hline
\end{tabular}

Note: * Statistically significant $(p<0.05)$ (chi-square test); * ${ }^{*}$ Statistically significant $(p<0.05)$ (Fisher's exact test).

Table 2 lists the parafunctions cited by students with TMD (DMF index). The highlighted lines emphasize the habits that showed a statistically significant association with the presence of TMD.

Regarding the most common symptoms, it was found that the most prevalent symptom was fatigue during mastication $(28.7 \%)$, followed by the noise feeling in the temporomandibular joint during movements $(17.1 \%)$ and pain for chewing (14\%). Table 3 shows the relationship between parafunctional habits and issues that assessed the TMD symptoms, adapted from previous studies ${ }^{11-13}$, presenting only statistically significant relationships by the chi-square test. It was found that the habit which was associated with the highest number of symptoms was the prone sleeping position. The symptoms most commonly associated with habits were pain while resting and fatigue during chewing.

Regarding the signals obtained in clinical examination, it was found that $59.2 \%$ of the sample were sensitive to palpation and $48.8 \%$ presented joint signals. Table 4 shows the relationship among joint and muscle signals and the gender, stress and habits variables. There was a statistically significant relationship only between muscle sensitivity to palpation and gender $(p=0.01)$, with a higher prevalence of sensitivity to palpation in women. There was no association between joint signs and the aforementioned variables.

Regarding the association of habits with clinical signs, it was found only statistically significant relationship between unilateral chewing and muscle tenderness ( $p$ $=0.045$ ) as well as between the chewing lollipops habit / ice and muscle tenderness $(p=0.04)$. No habit presented significant relationship with joint signs.

Chart 1 shows the relationship among parafunctional habits. There was a statistically significant association among various parafunctional habits. Chewing ice / lollipops was the habit which had more association with other habits like teeth grinding, teeth clenching, biting objects, chewing gum, cheek biting, tongue thrusting, lip sucking and prone sleeping position. In return, the unilateral chewing habit was not statistically related to any of the other habits mentioned. 
Table 2. Relationship between the presence of symptoms of TMD (DMF index) and parafunctional habits João Pessoa (PB), 2010.

\begin{tabular}{|c|c|c|c|c|c|c|c|}
\hline \multirow{2}{*}{\multicolumn{2}{|c|}{ Habits }} & \multicolumn{6}{|c|}{ TMD symptons } \\
\hline & & \multicolumn{2}{|c|}{ no } & \multicolumn{2}{|c|}{ Yes } & \multirow{2}{*}{ value of $p$} & \multirow{2}{*}{ IC $95 \%$} \\
\hline & Presence & $\mathbf{n}$ & $\%$ & $\mathbf{n}$ & $\%$ & & \\
\hline \multirow{2}{*}{ teeth grinding } & No & 17 & 13,2 & 89 & 69,0 & \multirow{2}{*}{0,719} & \multirow{2}{*}{$0,34-4,7$} \\
\hline & yes & 3 & 2,3 & 20 & 15,5 & & \\
\hline \multirow{2}{*}{ teeth Clenching } & No & 18 & 14 & 81 & 62,8 & \multirow{2}{*}{0,158} & \multirow{2}{*}{$0,67-14,26$} \\
\hline & Yes & 2 & 1,6 & 28 & 21,7 & & \\
\hline \multirow{2}{*}{ Biting nails } & No & 14 & 10,9 & 59 & 45,7 & \multirow{2}{*}{0,188} & \multirow{2}{*}{$0,70-5,52$} \\
\hline & Yes & 6 & 4,7 & 50 & 38,8 & & \\
\hline \multirow{2}{*}{ Biting objects } & No & 16 & 12,4 & 62 & 48,1 & \multirow{2}{*}{$0,042 * *$} & \multirow{2}{*}{$0,95-9,66$} \\
\hline & Yes & 4 & 3,1 & 74 & 36,4 & & \\
\hline \multirow{2}{*}{ Chewing gum } & No & 7 & 5,4 & 37 & 28,7 & \multirow{2}{*}{0,927} & \multirow{2}{*}{$0,38-2,85$} \\
\hline & Yes & 13 & 10,1 & 72 & 55,8 & & \\
\hline \multirow{2}{*}{$\begin{array}{l}\text { Biting the } \\
\text { cheecks }\end{array}$} & No & 19 & 14,7 & 74 & 57,4 & \multirow{2}{*}{$0,013 * *$} & \multirow{2}{*}{$1,15-69,8$} \\
\hline & Yes & 1 & 0,8 & 35 & 27,1 & & \\
\hline \multirow{2}{*}{ thumb sucking } & No & 20 & 15,5 & 106 & 82,2 & \multirow{2}{*}{1,0} & \multirow{2}{*}{$0,78-0,9$} \\
\hline & yes & 0 & 0 & 3 & 2,3 & & \\
\hline \multirow{2}{*}{$\begin{array}{l}\text { Resting chin on } \\
\text { hand }\end{array}$} & No & 10 & 7,8 & 59 & 45,7 & \multirow{2}{*}{0,73} & \multirow{2}{*}{$0,32-2,2$} \\
\hline & yes & 10 & 7,8 & 50 & 38,8 & & \\
\hline \multirow{2}{*}{ Tongue thrusting } & No & 18 & 14 & 92 & 71,3 & רד ת & י 72 \\
\hline & yes & 2 & 1,6 & 17 & 13,2 & 0,13 & $0,35-1,8$ \\
\hline lin curking & No & 15 & 11,6 & 45 & 34,9 & ( & 111250 \\
\hline LIP sucking & yes & 5 & 3,9 & 64 & 49,6 & $0,00 /^{*}$ & $1,4-12,58$ \\
\hline Unilateral & No & 18 & 14 & 91 & 70,5 & 073 & $037-835$ \\
\hline mastication & yes & 2 & 1,6 & 18 & 14 & 0,13 & נו \\
\hline Prone sleeping & No & 17 & 13,2 & 64 & 49,6 & 0 026* * * & 11,141 \\
\hline position & yes & 3 & 2,3 & 45 & 34,9 & 0,020 & $1,1-14,4$ \\
\hline chewing ice / & No & 13 & 10,1 & 42 & 32,6 & $0017 *$ & $109-802$ \\
\hline lollipops & yes & 7 & 5,4 & 67 & 51,9 & $0,04 \%$ & $1,09-0,02$ \\
\hline
\end{tabular}

Note: * Statistically significant $(p<0.05)$ (chi-square test); ** Statistically significant $(p<0.05)$ (Fisher's exact test).

Table 3. Symptoms of TMD and their relationship with parafunctional habits (statistically significant values). João Pessoa (PB), 2010.

\begin{tabular}{|c|c|c|}
\hline Habits & Symptons & values of $p$ \\
\hline \multirow{2}{*}{ Clenching the teeth } & Tiredness (fatique) during mastication & $0,043^{*}$ \\
\hline & Pain in the jaw or cheek at rest & $0,013^{*}$ \\
\hline Biting the cheecks & Tiredness (fatique) during mastication & 0,031 * \\
\hline Thumb sucking & Pain in the jaw or cheek at rest & $0,002^{*}$ \\
\hline \multirow[t]{2}{*}{ Prone sleeping position } & Tmj pain & $0,027^{*}$ \\
\hline & Pain in the jaw or cheek at rest & $0,048 *$ \\
\hline \multirow{2}{*}{ Chewing ice } & Tiredness (fatique) during mastication & $0,008^{*}$ \\
\hline & Pain in the jaw or cheek at rest & $0,007 *$ \\
\hline Prone sleeping position & Yes & $0,046^{*}$ \\
\hline
\end{tabular}

Note: * statistically significant $(p<0,05)$ (chi-square test). 
Table 4. Relationship between the presence of muscle signs and joint, gender and stress varialble and parafunctional habits. João Pessoa (PB), 2010.

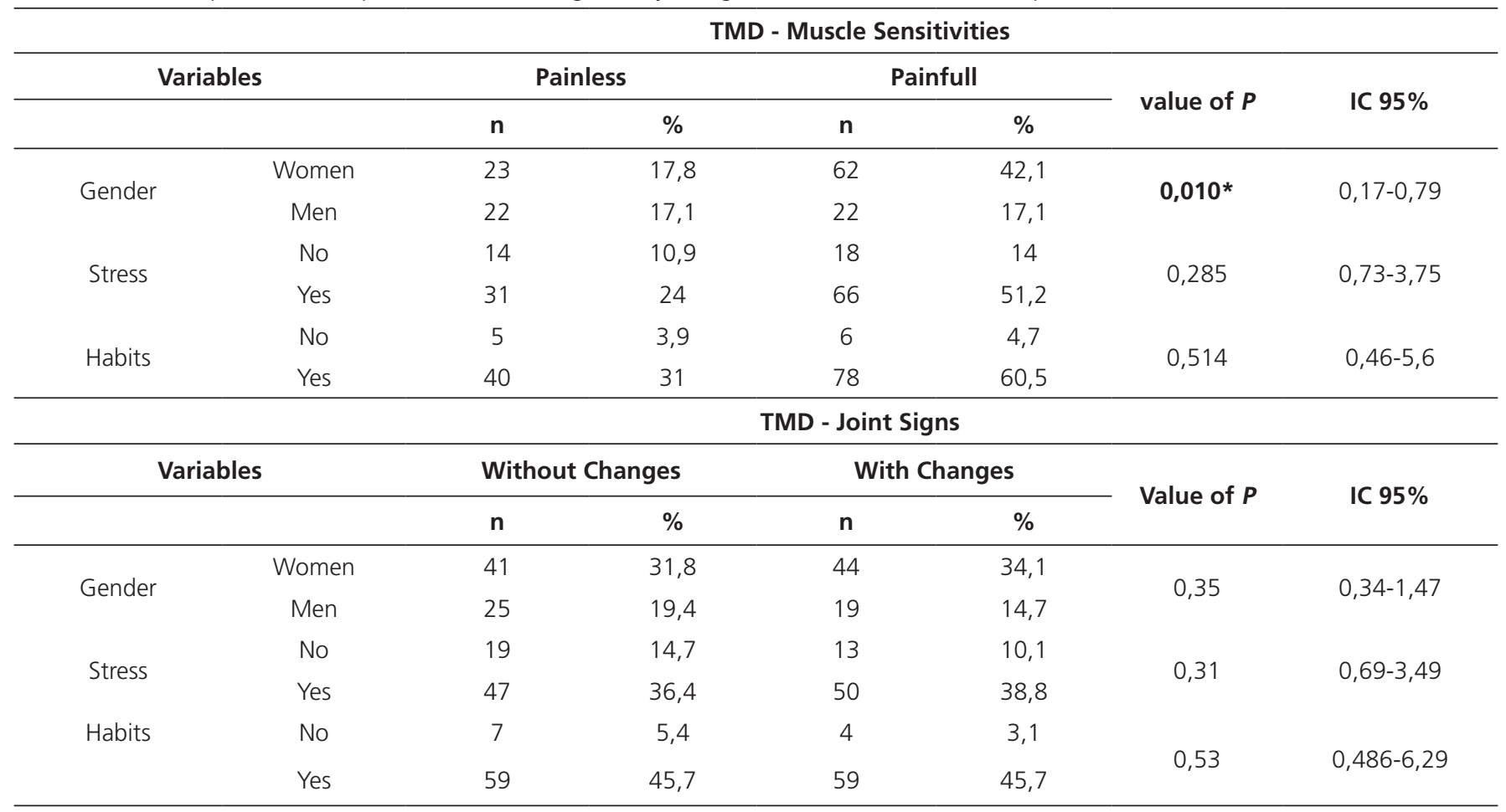

Note: * statistically significant $(p<0,05)$ (chi-square test).

Chart 1. Statistical Association between the various parafunctional habits. João Pessoa (PB), 2010.

\begin{tabular}{|c|c|c|c|c|c|c|c|c|c|c|c|c|c|}
\hline Habits & $\begin{array}{l}\text { Grinding } \\
\text { the teeth }\end{array}$ & $\begin{array}{l}\text { Clenching } \\
\text { the teeth }\end{array}$ & $\begin{array}{l}\text { Biting } \\
\text { nails }\end{array}$ & $\begin{array}{c}\text { Biting } \\
\text { objects }\end{array}$ & $\begin{array}{l}\text { Chewing } \\
\text { gum }\end{array}$ & $\begin{array}{l}\text { Biting } \\
\text { the } \\
\text { cheeks }\end{array}$ & $\begin{array}{l}\text { Thumb } \\
\text { sucking }\end{array}$ & $\begin{array}{l}\text { Resting } \\
\text { chin on } \\
\text { hand }\end{array}$ & $\begin{array}{l}\text { Tongue } \\
\text { thrusting }\end{array}$ & $\begin{array}{l}\text { Lips } \\
\text { sucking }\end{array}$ & $\begin{array}{l}\text { Unilateral } \\
\text { mastication }\end{array}$ & $\begin{array}{l}\text { Prone } \\
\text { sleeping } \\
\text { position }\end{array}$ & $\begin{array}{c}\text { Chewing } \\
\text { gum / } \\
\text { lollipop }\end{array}$ \\
\hline $\begin{array}{l}\text { teeth } \\
\text { grinding }\end{array}$ & - & 0,05 & NS & NS & NS & $<0,01$ & NS & NS & 0,06 & 0,02 & NS & NS & 0,01 \\
\hline $\begin{array}{l}\text { teeth } \\
\text { clenching } \\
\text { the }\end{array}$ & & - & NS & NS & 0,02 & $<0,01$ & NS & NS & $<0,01$ & 0,01 & NS & NS & 0,02 \\
\hline Biting nails & & & - & 0,006 & NS & NS & NS & NS & NS & NS & NS & NS & NS \\
\hline $\begin{array}{l}\text { Biting } \\
\text { objects }\end{array}$ & & & & - & 0,022 & 0,027 & NS & NS & NS & 0,007 & NS & 0,001 & 0,002 \\
\hline $\begin{array}{l}\text { Chewing } \\
\text { gum }\end{array}$ & & & & & - & 0,003 & NS & 0,009 & NS & $<0,01$ & NS & 0,021 & $<0,01$ \\
\hline $\begin{array}{l}\text { Biting the } \\
\text { cheeks }\end{array}$ & & & & & & - & NS & NS & 0,004 & NS & NS & NS & 0,001 \\
\hline $\begin{array}{l}\text { Thumb } \\
\text { sucking }\end{array}$ & & & & & & & - & NS & NS & NS & NS & 0,049 & NS \\
\hline $\begin{array}{l}\text { Resting } \\
\text { chin on } \\
\text { hand }\end{array}$ & & & & & & & & - & NS & NS & NS & 0,018 & NS \\
\hline $\begin{array}{l}\text { Tongue } \\
\text { thrusting }\end{array}$ & & & & & & & & & - & 0,001 & NS & NS & 0,012 \\
\hline $\begin{array}{l}\text { Lip } \\
\text { sucking }\end{array}$ & & & & & & & & & & - & NS & NS & 0,012 \\
\hline Unilateral & & & & & & & & & & & & & \\
\hline mastication & & & & & & & & & & & - & 0,01 & NS \\
\hline $\begin{array}{l}\text { Prone } \\
\text { sleeping } \\
\text { position }\end{array}$ & & & & & & & & & & & & - & 0,01 \\
\hline
\end{tabular}

Note: NS- Not significant. 


\section{DISCUSSION}

In the present study the sample consisted predominantly of female students due to their openness to volunteer, making it difficult to obtain an equivalent sample by gender. One of the limitations of the study was the relatively low participation of students, considering that the available time for the examinations without compromising their class attendance, was the time break between classes.

The temporomandibular disorders (TMD) has a multifactorial characteristic and for its proper diagnosis, it is necessary a detailed patient history, so the use of questionnaires to TMD diagnosis has been valuable at this stage. The TMD should be diagnosed as early as possible in the population because late diagnosis can lead to a state of bigger commitment of these pathologies.

It is difficult to compare the results in TMD research due to a lack of standardization in diagnostic criteria, as highlighted by Marchioriet al. ${ }^{11}$. Other autores ${ }^{2,17}$ have already used in their research the questionnaire recommended by Fonseca et al. ${ }^{15}$, known as DMF index, which according to Vasconcelos et al. ${ }^{18}$ allows you to sort the individual with TMD at an early stage.

However, temporomandibular dysfunction is characterized by the presence of clinical signs such as joint sounds, mouth opening limitation, mandibular deviations, changes in masticatory functions, palpation pain in the mastication muscles, palpation pain of $\mathrm{TMJ}^{16-18}$, and these can only be observed by clinical examination, as used by Lemos et al. ${ }^{16}$

The index used in this study allowed us to distinguish the different degrees of dysfunction, besides enabling comparison with other studies of the same type. Regarding the degree of TMD, it was found that most of the subjects showed mild TMD (54.3\%), while $24 \%$ had moderate TMD and $6.2 \%$ severe TMD, and only $15.5 \%$ showed no degree of TMD. A higher percentage of subjects with mild TMD, in relation to other TMD levels, was also observed by Nomura et al. ${ }^{2}$ and Oliveira et al. ${ }^{17}$, who also used Fonsecas et al. ${ }^{15}$ questionnaire to assess the prevalence and degree of TMD.

Fonseca et al. ${ }^{15}$ claimed that individuals with moderate and severe TMD should be referred to specialized treatment centers. In this study, a total of $31.1 \%$ of subjects were in need for treatment. This result was higher than those reported by Nomura et al. ${ }^{2}$ and Oliveira et al. ${ }^{17}$ that found a lower percentage of individuals in need for treatment, with values of $18.24 \%$ and $17.43 \%$, respectively.

According to this study, it was found the presence of some degree of TMD by the DMF index in $84.5 \%$ of the specimen, but most of them had a low index of TMD. The results refute Godoy's et al. ${ }^{19}$ score, who found a prevalence of $16.3 \%$ in a population of adolescents by the DMF index. One possible reason for this difference may lie in the fact that the DMF index, due to its high sensitivity and low specificity can result in false positive ${ }^{14}$, and thus has a tendency to overestimate its prevalence, so it is necessary to confirm the diagnosis through a clinical exam. This fact turns out to be confirmed by a clinical exam, which showed a lower percentage of muscular TMD and joint signs.

This data is also relatively high when compared with Fernandes et al. ${ }^{20}$ study that brings the prevalence of TMD in adolescents being 25.5\%, evaluated by RDC / TMD. This difference can be given by the differences between the diagnostic methods used, as pointed out by the Seine et al. ${ }^{4}$, who in a review of 17 studies published between 1990 and 2012, which evaluated the prevalence of TMD in children and adolescents, found that the prevalence DTM ranged from $16 \%$ to $68 \%$.

The values found in clinical exams of muscle tenderness (59.2\%) and joint signs (48.8\%) are within this range of prevalence reported by the Seine et al. ${ }^{4}$ and should be considered as more reliable data of the real presence of alterations related to TMD. Gavish et al. ${ }^{8}$ showed a lower prevalence of muscle tenderness in his study sample (23.4\%), while for Winocur et al. ${ }^{13}$ these values ranged from $18 \%$ (men) to $43 \%$ (women). In relation to gender, literature presents countless researches which show the occurrence of female predominance ${ }^{1-2,5-6,12-13,17}$. This study also showed a statistically significant relationship ( $p=0.032$ ) between TMD and gender (women). It is due to the fact that women patients usually look for treatment and have different physiological characteristics such as lower pain threshold and more vulnerability to stress ${ }^{6,13}$. In addition, hormonal factors may be linked to pain and the development of TMD².

For the symptoms described by patients, Nomura et al. ${ }^{2}$ found a higher prevalence of joint noise $(65.52 \%)$, followed by headache (64.55\%), than this study. However, their sample was young adults around 20 years old. On the other hand, Bonjardim et al. ${ }^{21}$ also found these signals in adolescents, $26.72 \%$ for joint noises and $21.65 \%$ for headaches, corroborating the findings of this study which were $25.6 \%$ and $20.9 \%$, respectively. Other studies have also found joint noises ${ }^{21}$ and headaches ${ }^{22}$ as prevalent symptoms, being joint noises the most common one.

Several factors are involved in the development of a disorder, but it is not easy to establish a relationship 
between TMD and parafuncional habits ${ }^{23}$. There was a high incidence of adolescents who had some parafunctional habits $(91.4 \%)$ close to the value $(94 \%)$ found by Rodrigues et al. ${ }^{24}$ value which is considerably higher than that $(75 \%)$ found by Figueiredo et al. ${ }^{1}$. Our results agree with Gavish's et al. ${ }^{8}$, Winocur's et al. ${ }^{13}$ and Rodrigues et al. ${ }^{24}$ who claim that the parafunctional habits are very common in adolescents. Other studies show that there is a relation of parafunctional habits as contributing factors which predispose the TMD, or that are considered risk factors $5-6,13,22,25$, which is consistent with this study that found a significant correlation among the presence of parafunctional habits and the presence of TMD signs and symptoms. It is known that parafunctional habits provide maintenance and / or progression of pain in TMD, leading to muscle overload and consequently to worsening the disorder, as pointed out by Fernandes et al. ${ }^{20}$, when it was related to the presence of parafunctional habits and TMD in adolescents.

There was no statistically significant association between the presence of parafunctional habits and clinical signs of TMD (muscle tenderness or changes in TJM). However, there was a statistically significant relationship analyzing the habits individually, that is, chewing ice / lollipops had association with muscle tenderness to palpation, relationship also found by Gavishet al. ${ }^{8}$; and unilateral chewing was also related to muscle tenderness. This fact probably occurs because during the unilateral chewing there is an overload of the muscles of mastication on the side where this is practiced, and there is an overload of the muscles in individuals who habitually chew ice / lollipops making them more susceptible to sensitivity.

In this study the presence of emotional stress was $75.2 \%$ of the sample and this had a statistically significant relationship with TMD and the need for treatment. Thus, observing that individuals with TMD had emotional stress and individuals with more incidence of severe TMD were also stressed people. Studies state that stress has a great influence in TMD, which acts as an etiologic factor for generating parafunctional habits, and that is an aggravating factor of the pathological state, bringing an impact on life quality and consequently, social life of the individual-7,10-12. The theme TMD in adolescents is still little studied in Brazil and worldwide. When we refer to studies conducted in Brazil, just a few are found ${ }^{3,20-22}$ and they do not bring a TMD diagnostic methodology with the presence of clinical examination protocols. It is suggested the accomplishment of further studies addressing larger (so that the data can be more accurate to the real TMD condition in adolescents), probabilistic samples(allowing a more accurate extrapolation of the results to the Brazilian population) and longitudinal samples (to assess the causes and real effects of habits in the development and maintenance of TMD), besides clinical evaluation for the diagnosis of TMD, since most use selfassessment questionnaires.

Due to the high prevalence of parafunctional habits, signs and symptoms of TMD in the sample, it is recommended the inclusion of the TMD diagnostic examination in the dental routine inspection. It is also suggested that there is a need of clarification by dentists regarding signs and symptoms of TMD, and the need for early diagnosis of TMD to prevent further damage to the stomatognathic system

Similarly, it is important some clarification regarding parafunctional habits and the potential risks they may pose for the development of future problems. Considering that they are a risk factor in the etiology of TMD, it is necessary to inform students and teachers through a work of education and prevention of the dysfunction to avoid more serious damage. It can also be suggest that the TMD should be seen as a public health ${ }^{3}$ problem due to its high prevalence in some degree $(84.5 \%)$, the high prevalence of parafunctional habits $(91.5 \%)$, muscle tenderness (59.2\%) and joint signs (48.8\%) in the sample evaluated. Unfortunately, the TMD examination has not been included in the National Oral Health Survey yet - the SB Brazil, conducted in 2003 and 2010. It also points out that there is a need to include specialized services to take care of TMD patients in public service because of its high prevalence.

\section{CONCLUSION}

Thus, it is concluded that there was a high prevalence of signs and symptoms of TMD and parafunctional habits in the sample investigated, and there is an association with women, emotional stress and the presence of parafunctional habits. There was also an association between women and muscle tenderness, as well as some association between some functional habits and muscle tenderness. It is necessary to establish public policies of prevention and access to treatment for this problem and specific age group.

\section{Collaborators}

B OLIVEIRA and FDS FORTE participated in the project design, study design, data collection and analysis; JAS LIMA, 
PLP SILVA and PRF BONAN contributed to the data analysis (descriptive and statistical) data interpretation, writing and reviewing the manuscript. AUD BATISTA guided all stages

\section{REFERENCES}

1. Figueiredo VMG, Cavalcanti A, Farias ABL, Nascimento SR Prevalência de sinais, sintomas e fatores associados em portadores de disfunção temporomandibular. Acta Scientiarum. 2009;31(2):159-63

2. Nomura K, Vitti $M$, Oliveira AS, Chaves TC, Semprini $M$, Siéssere $\mathrm{S}$, et al. Use of the Fonseca's Questionnaire to acess the prevalence and severity of temporomandibular disorders in Brazilian dental undergraduates. Braz Dent J. 2007;18(2):16367. doi: 10.1590/S0103-64402007000200015

3. Carrara SV, Conti PCR, Barbosa JS. Termo do $1^{\circ}$ Consenso em disfunção temporomandibular e dor orofacial. Dental Press J Orthod. 2010;15(3):114-20.

4. Sena MF, Mesquita KSF, Santos FRR, Silva FWGP, Serrano KVD. Prevalência de disfunção temporomandibular em crianças e adolescentes. Rev Paul Pediatr. 2013;31(4):538-45.

5. Carvalho LPM, Piva MR, Santos TS, Ribeiro CF, Araújo CFR, Souza LB. Estadiamento clínico da disfunção temporomandibular: estudo de 30 casos. Odontol Clín Científ. 2008;7(1):47-52.

6. Karibe H, Shimazu K, Okamoto A, Kawakami T, Kato Y, WaritaNaoi. Prevalece and association of self-reported anxiety, pain, and oral parafunctional habits with temporomandibular disorders in Japanese children and adolescents: a cross-sectional survey. BMC Oral Health. 2015;15:8. doi: 10.1186/1472-6831$15-8$

7. Gui MS, Pimentel MJ, Gama MCS, Ambrosano GMB, Barbosa CMR. Quality of life in temporomandibular disorder patients with localized and widespread pain. Braz J Oral Sci. 2014;13(3):193-97.

8. Gavish A, Halachmi M, Winocur E, Gazit E. Oral habits and their association with signs and symptoms of temporomandibular disorders in adolescent girls. J Oral Rehabil. 2000;27(1):22-32. doi: 10.1046/j.1365-2842.2000.00484.x

9. Winocur E, Gavish A, Finkelshtein T, Halachmi M, Gazit E. Oral habits among adolescent girls and their association with symptoms of temporomandibular disorders. J Oral Rehabil. 2001;28(7):624-29. doi: 10.1046/j.1365-2842.2001.00708.x

10. Suvinen TI, Nyström M, Evãlahti M, Kleemola-kujala E, Waltimo A, Könönen M. A 8 year follow up study of temporomandibular disorder and psychosomatic symtoms from adolescence to Young adulthood. J Orofac Pain. 2004;18(2):126-30.

11. Marchiori AV, Garcia AR, Zuim RJ, Fernandes AUR, Cunha LDP. Prevalência de sinaisesintomas da disfunção temporomandibular e ansiedade: estudantes brasileiros do ensino fundamental. RGO, Rev Gaúch Odontol. 2007;55(3):257-62

12. Resende CMBM, Alves ACM, Coelho LT, Alchieri JC, Roncalli AG, Barbosa GAS. Quality of life and general health in patients with temporomandibular disorders. Braz Oral Res. 2013:27(2):116-21. of research from conception and design of the project, data collection, data analysis, writing and final revision of the text. All authors reviewed the text and approved its final version.

13. Winocur E, Littnerusb D, Adamsusb I, Gavish A. Oral habits and their association with signs and symptoms of temporomandibular disorders in adolescents: a gender comparison. Oral Surg Oral Med Oral Pathol Oral Radiol Endod. 2006;102(4):482-87. doi: 10.1016/j.tripleo.2005.11.007

14. Chaves TC, Oliveira AS, Grossi DB. Principais instrumentos para avaliação da disfunção temporomandibular, parte I : índices e questionários; uma contribuição para a prática clínica e de pesquisa. Fisioter Pesqui. 2008;15(1):92-100.

15. Fonseca DM, Bonfante $G$, Valle AL, Freitas SFT. Diagnóstico pela anamnese da disfunção craniomandibular. RGO, Rev Gaúch Odontol. 1994;42:23-8.

16. Lemos GA, Moreira VG, Forte FDS, Beltrão RTS, Batista AUD. Correlação entre sinais e sintomas da Disfunção Temporomandibular (DTM) e severidade da má oclusão. Rev Odontol UNESP. 2015;44(3):175-80.

17. de Oliveira AS, Dias EM, Contato RG, Berzin F. Prevalence study of signs and symptoms of temporomandibular disorder in Brazilian college students. Braz Oral Res. 2006;20(1):3-7. doi: 10.1590/S1806-83242006000100002

18. Vasconcelos BCE, Silva EDO, Kelner N, Miranda KS, Silva AFC Meios de diagnóstico das desordens temporomandibulares. Rev Cir Traumatol Buco-Maxilo-Facial. 2002;1(2):49-57.

19. Godoy F, Rosenblat A, Godoy-Bezerra J. Temporomandibular disorders and associated factors in Brazilian teenagers: a crossectional study. Int J Prosthodont. 2007;20(6):599-604.

20. Fernandes G, van Selms MK, Gonçalves DA, Lobezoo F, Camparis CM. Factors associated with tempormandibular desorders pain in adolescents. J Oral Rehabil. 2015;42(2):11319. doi: 10.1111/joor. 12238

21. Bonjardim LR, Gavião MB, Pereira LJ, Castelo PM, Garcia RC. Signs and symptoms of temporomandibular disorders in adolescents. Braz Oral Res. 2005;19(2):93-8.

22. Tosato JP, Biasotto-Gonzalez DA. Symptomatology of the temporomandibular dysfunction related to parafunctional habits in children. Braz J Oral Sci. 2005:4(14):787-90.

23. Melo GM, Barbosa JFS. Parafunção × DTM: a influência dos hábitos parafuncionais na etiologia das desordens temporomandibulares. POS - Perspect Oral Sci. 2009;1(1):438.

24. Rodrigues PTS, Souza AC, Ninno CQMSD. Ocorrência de hábitos orais deletérios em adolescentes do ensino médio. Rev CEFAC. 2004;6(4):376-81.

25. Kobs G, Bernhadrt O, Kocher K, Meyer G. Oral parafunctions and positive clinical examination findings. Stomatologija. 2005;7(3):81-3.

Received on: 9/6/2015 Final version resubmitted on: 1/9/2015 Approved on: 16/10/2015 